\title{
EFFECTS OF SUBCATEGORICAL CUES ON THE RELEASE OF PROACTIVE INHIBITION
}

\author{
TOSHIAKI MORI ${ }^{1}$
}

Fukwoka thinersion of Education

\begin{abstract}
The effects of subcategorical cues on the rclease from proactive inhibition were examined. Analysis of variance with $2 \times 2$ factorial design was employed, in which the presence or absence of subcategorical change and of subcategorical cues at the time of recall of the release trial were main sources. Results indicated that the presence of the subcategorical cues produced a substantial degree of PI release when the subcategory was changed, while there was no such PI release when the subcategory was not changed. These results were interpreted as a support for the hypothesis that subcategorical cues aid recall in terms of response-selection-function of the cues.
\end{abstract}

In the Brown-Peterson paradigm (Brown, 1958; Peterson \& Peterson, 1959), the subjects are briefly shown a stimulus (e.g., a consonant trigram) and, following filled retention interval, are tested for recall. Using this paradigm, Keppel and Underwood (1962) showed that recall performance after an 18 -sec interval declined markedly over the first few trials. This decrease in recall over trials has been called the buildup of proactive inhibition (PI). Subsequently, Wickens (1970) showed that the rapid accumulation of PI depended upon the similarity, across trials, of the to-be-remembered (TBR) items and, further, that performance could be restored almost to the original level if, on the next trial, the TBR items were drawn from a different class. Wickens (1970) viewed this " release from PI" phenomenon as useful in determining the encoding dimension of linguistic material. Although there are now considerable data on the PI effect and the release from PI effect, attempts to explain the phe-

1 The author is grateful to Tetsuyo Sugitani, Shoji Honjo, Yoneko Mizuochi, Junko Miyahara, Sumi Mohri, and Fukumi Yoshikawa for their assistance in the data collection and analysis. Special thanks are also due to Sachio Nakamizo for his helpful comments on an earlier draft of this paper.

Requests for reprints should be sent to Toshiaki Mori, Department of Psychology, Fukuoka University of Education, 729, Akama, Munakata-Cho, Munakata-Gun, Fukuoka, 811-41 Japan. nomena have met only modest success. Postman (1975) recently reviewed a number of possible explanations and concluded that "the total picture remains blurred".

Three types of theories have so far been proposed to explain PI effect and release from PI effect, namely, attentional hypothesis, storage hypothesis, and retrieval hypothesis. The attentional hypothesis proposed that subject becomes bored or inattentive because of the continuing presentation of items from the same class and hence performs less well, but perceptually alerted by the change in TBR items at the critical trial, and consequently the new TBR items are better registered in memory.

The storage hypothesis places the locus of PI and release from PI in storage stage (Conrad, 1967). PI, according to this hypothesis, is due to the depressed efficiency in transfering the target item from a short-term to long-term store (e.g., Atkinson \& Shiffrin, 1968) because of the continuing presence in short-term store of items from previous trials that are similar to the target item. If there is any change in the nature of the current target item to make it more dissimilar than previous items, there would be less competition between memory traces in the short-term store. Consequently, the target item would have better transfer to long-term store.

However, a number of recent studies have made the strong claim that PI and release 
from II are cxclusively retricval problems (Bennctt, 1975; Gardines, Craik, \& Birtwistle, 1972; Hawkins, Pardo, \& Cox, 1972; Loftus \& Patterson, 1975; Turvey, Mosher, \& Katz, 1971; Watkins \& Watkins, 1975). Thus, the weight of the available cvidence may be interpreted to favor the retrieval hypothesis. Especially, Gardiner et al. (1972) presented data sharply at odds with the attentional and storage hypotheses. In their experiment, the Brown-Peterson paradigm was used to investigate the release from $P I$ as a function of the availability of a subcategory cue. The subcategory cue was presented (1) at input only; (2) at output only; or (3) neither at input nor output. There was release from PI for both Group 1 and Group 2, but not for Group 3. The differences between Group 2 and Group 3 showed clearly that the buildup and release of PI originate at retrieval process since both of these groups were treated identically until the time of recall on the relcase trial.

It should be noted, however, that Gardiner et al. (1972) did not settle the important issue of how the retrieval cues functioned in their $\mathrm{cx}$ periment. It is generally assumed that recall involves both search and decision phases. Therefore, two functions of retrieval cues should be taken into consideration. First, it is possible that the cues served to facilitate search phases, increasing number of words for subject to consider as responses. Secondly, it is also possible that the cues served to facilitate decision phases, helping to discriminate current items from previous items. In order to detcrmine whether the cues increase accessibility to the stored items (i.e., response-generation function of the cues) or to help to discriminate current items from previous items (i.e., response-selection function of the cues), Dillon and Bittner (1975) introduced the conditions in which subset cues were provided without any changes of the subset. They found that subcategory cues produced a substantial PI release under these conditions, and suggested that the increase of recall by provision of the cues should be the results of increased accessibility to the stored items since the cues could not possibly distinguish present from previous items. However, an important point that should be kept in mind while considering their findings is that the subjects who noticed the subcategorical structure of the lists were not discarded in their study. It seems probable that some subjects in their study noticed the subcategorical structure of the list at input phase on Trial 4 and encorded the material in terms of the appropriate subcategory, consequently producing enhanced recall on Trial 4. In the present study, therefore, the effects of subcategory cues upon the relcase from PI were reexamined under the condition that the subjects who reported awareness of the subcategorical structure of the lists were discarded from data analysis.

\section{Method}

\section{Subjects}

Subjects were 64 students (32 male, 32 female) at Fukuoka University of Education. None of them had previously participated in an experiment on memory. Equal number of males and females were assigned to each of the four groups of 16 subjects. Additional 19 subjects were run but discarded because they reported that they had noticed the subcategorical structure of the lists: Five in Shift-Cue group, three in Shift-No Cue group, eight in No Shift-Cue group, and three in No Shift-No Cue group. Eight of these 19 subjects noticed the subcategorical shift at input phase on Trial 4 , and the remaining 11 subjects noticed that all of the TBR items on Trial 4 were drawn from the same subcategory.

\section{Materials}

A total of 24 words which were all the names of foreign cities were selected from the word pool of Mori (1974). These foreign cities consisted of 12 American cities and 12 European cities. These 12 words from each subcategory were divided into four triads. The four triads were selected so that the total number of times the three words had been given as instances of the category was approximately equal across triads. Sixteen different lists were constructed so that each triad appeared in each of four 
positions an equal number of times. Of the 16 lists, half the lists were used in Shift conditions, and half in the No Shift conditions. Of the eight lists employed in the Shift conditions, half had a shift from one subset to the other, and half in the reverse direction. All stimulus material was presented to subject on a memory drum.

\section{Design and Procedure}

The design was a $2 \times 2$ factorial in which the presence (Shift) or absence (No Shift) of sub. category change on Trial 4 was one factor, and the presence (Cue) or absence (No Cue) of subcategory cue at the time of recall on Trial 4 was the second factor.

Each subject was tested individually. After subject was seated on the chair, he was informed that the experiment was concerned with their ability to simultaneously do mental arithmetic and remember words and that both were equally important. The subject was informed of the category nature of the TBR material, and was also informed that the category would remain unchanged over successive trials. The subject was given practice on the mental arithmetic distractor task (counting backwards by threes from a three-digit number) on which both speed and accuracy were stressed. Following this, the subject was given the four Brown-Peterson trials. When the trial began, three asteriscs appeared for $2 \mathrm{sec}$ as a ready signal. Next followed a $2 \mathrm{sec}$ period during which the general category cue "foreign cities" was shown: This general category cue was not shown on Trial 2, Trial 3, and Trial 4. This was followed by a word trigram which also appeared for $2 \mathrm{sec}$. A three-digit number was then presented for $14 \mathrm{sec}$, and the subject had to say it aloud and then count backwards by threes from this number as rapidly and accurately as possible. Three question marks were then presented for $10 \mathrm{sec}$, which was the signal to recall the words presented at the beginning of the trial. Following the 10 -sec recall interval, three asteriscs were again shown, signaling the next trial. On Trial 4, the TBR material shifted from one subset to another subset for Shift con- ditions (i.e., Shift-Cue and Shift-No Cue), while the subset change did not occur for No Shift conditions (i.e., No Shift-Gue and No Shift-No Cue). The subjects in the Cue conditions (i.e., Shift-Cuc and No Shift-Cue) were provided with the subcategory cue (American city or European city) at the time of recall on Trial 4, but the subjects in the No Cue conditions (i.e., Shift-No Gue and No Shift-No Cue) were not provided with this cue. Following Trial 4, the subject was given a sheet of paper on which all 12 words from the four trials were listed in random order. The subject was instructed to decide for each word whether he had seen that word on Trial 1, Trial 2, Trial 3 , or Trial 4 .

\section{Results}

The recall was scored in terms of the percentage of words recalled regardless of output order. The percentage correct recall for each group as a function of trials is shown in Fig. 1. Considering first the development of PI over the first three trials, it is clear that there was a

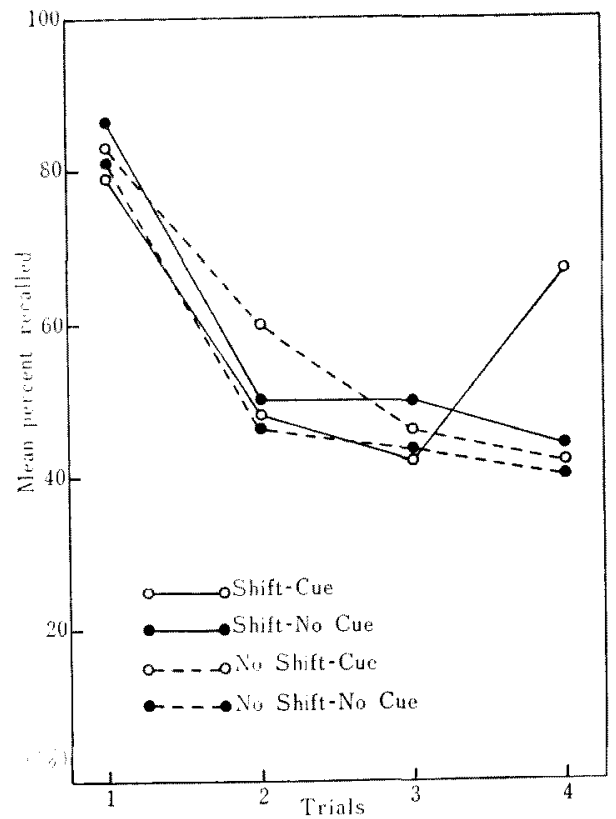

Fig. 1. Mean percentage of recalls for each condition as a function of trials. 
TABLE 1

Total number of intra-list and extra-list intrusions (Numbers in parentheses denote extra-list intrusions)

\begin{tabular}{lcc}
\hline \multicolumn{1}{c}{ Conditions } & \multicolumn{2}{c}{ Trials } \\
& $1-3$ & 4 \\
\hline Shift-Cur & $8(8)$ & $0(3)$ \\
Shift-No Cue & $10(5)$ & $6(0)$ \\
No Shift-Cue & $11(3)$ & $9(0)$ \\
No Shift-No Cue & $12(5)$ & $13(0)$
\end{tabular}

decline in recall over those trials. A $4 \times 3$ analysis of variance which includes four groups as between-subjects variable and three trials as within-subjects variable were performed on data from Trials 1 to 3 . This analysis showed that the main effect of trials was statistically significant, $F(2,120)=25.10, p<.01$, but the main effect of groups and the interaction between trials and groups were not significant. Thus, there was a reliable buildup of PI over the first three trials and the comparability of groups was supported.

The main concern of the experiment was the performance on Trial 4. As is apparent from the figure, the Shift-Cue group showed a substantial amount of release from PI on Trial 4 whereas the other threc groups continued to decline on Trial 4. An analysis of variance performed on the data from Trial 4 yielded a significant effect of group, $F(3,60)=3.21, p<$ 05. The main effect of groups was further analysed with Newman-Kruls tests. These tests showed that Shift-Cue group recalled more words than the other three groups ( $/ s<$ $.05)$ while these three groups were not different from each other. Furthermore, separate Newman-Keuls tests performed on the differences between Trials 3 and 4 for the individual groups indicated that there is a increment in performance on Trial 4 for the Shift-Cue group $(p<.05)$, although no increases were observed for the other three groups.

Total number of intra-list and extra-list intrusions for each group is shown in Table 1 . Most of the intra-list intrusions are the intrusions from the previous trials. The major findings of interest is that the number of intra-
TABLE 2

Mean percentage of erroncous assignments

\begin{tabular}{lcccc}
\hline \multicolumn{1}{c}{ Conditions } & \multicolumn{4}{c}{ Trials } \\
\cline { 2 - 5 } & 1 & 2 & 3 & 4 \\
\hline Shift-Cuc & 41.7 & 56.3 & 60.4 & 10.4 \\
Shift-No Cue & 45.8 & 68.8 & 64.6 & 35.4 \\
No Shift-Cue & 60.4 & 60.4 & 64.6 & 62.5 \\
No Shift-No Cue & 47.9 & 72.9 & 52.1 & 52.1
\end{tabular}

list intrusions in Shift-Cue group decreased to zero on Trial 4, although the other groups continued to show several intra-list intrusions on Trial 4.

Performance on the final item-discrimination task, in which the subjects were to decide for each word from the four trials on which trial they had seen that word, was scored with respect to the percentage of error assignment. Thus, the performance on this task would provide a index of subjects' final knowledge regarding the relationship between triads. The percentage error assignment for each group as a function of trials is shown in Table 2. The crucial data to note in Table 2 is that the Shilt-Cue group performed better on Trial 4 items than the other three groups $\left(\chi^{2}=8.48\right.$, $p<.01)$.

\section{Discussion}

The first concern of the present study was to determine whether facilitating effect of the subcategory cue depended upon the subcategory change on the release trial. The results indicated that PI release occurred in Shift-Cue condition, but PI release was not observed in No Shift-Cue condition. The finding that the subcategory cue provided at the time of recall produced substantial PI release in Shift-Cue condition is consistent with that obtained in Gardiner et al. (1972) experiment. Since it would be reasonable to assume that there was no systematic differences between Shift-Cue and Shift-No Cue conditions in the manner in which the release-trial materials had been encoded, the data obtained in this study should be interpreted as supporting the notion of 
Gardiner et al. (1972) that PI release is a retrieval phenomenon.

Consider now the issue of how the subcategory cue functioned in this study. As Gardiner et al. (1972) noted, an important question concerning this issue is whether the subcategory cue influenced recall in terms of response generation or response selection. In other words the cue may increase accessibility to stored items and cue may also serve to discriminate current items from previous items. Part of the answer to this question would be provided by the findings that $P I$ release was not observed when the subcategory did not change. If the subcategory cue functioned as an aid in generating the otherwise inaccessible items, PI release would be expected even if the subcategory was not changed. If, however, the subcategory cue functioned as an aid in selecting the current items from previous items, little $\mathrm{PI}$ release would be expected in No Shift-Cue condition since the cue would not aid in selecting among alternatives under this condition. Therefore, the present findings that the provision of the subcategory cue did not produce PI release in No Shift-Cue condition should be interpreted in terms of response selection function of the cue. This interpretation might bc also supported by the fact that the subjects in No Shift-Cue condition continued to show several intra-list intrusions and did not enhance their performance on the item-discrimination task on Trial 4 items even though they were provided with the subcategory cue.

However, it should be noted that Dillon and Bittner (1975) reported that the subcategory cue enhanced performance whether there was a shift or not. The discrepancy between the present findings and those of Dillon and Bittner (1975) is probably due to the methodological difference that the subjects who might have noticed the subcategorical structure of the lists were not discarded in the study of Dillon and Bittner (1975) whereas the subjects who reported awareness of subcategorical structure of the lists were discarded from data analysis in the present study. Therefore, it might be tentatively concluded that appropriate encoding of the material in terms of the subcategory cue may be necessary for the subcategory cue to function as an aid in gencrating items. In summary, the present experiment, together with that of Dillon and Bittner, suggests that the subcategory cue may increase accessibility to stored items if the TBR items were encoded in terms of the subcategory cue, and that the cue may also function as an aid in selecting items whether the items are encoded in terms of the subcategory cue or not. This notion is somewhat analogous to "cncoding specificity" principle (Tulving \& Thomson, 1973) where it has been strongly suggested that cues presented at recall will improve recall only if the words to be learned were encoded with respect to these cues at the time of learning. At present, however, this notion remains at a speculative level because the evidence supporting this notion in the present study comes from subject's introspective reports.

\section{REFERENCES}

Atkinson, R. C., \& Sumfrin, R. M. 1968 Human memory: A proposed system and its control processes. In K. W. Spence \& J. T. Spence (Eds.), The Psychology of learning and motivation. Vol. 2. New York: Academic Press.

Bennett, R. W. 1975 Proactive interference in short-term memory: Fundamental forgetting processes. Journal of Verbal Learning and Verbal Beluwior, 14, 123-144.

Brown, J. 1958 Some tests of the deray theory of immediate memory. Quterly Journal of Experimental Psychology, 10, 12-21.

Conrad, R. 1967 Interference or decay over short rate intervals? Journal of Verbal Learning and Verbal Behavior, 6, 49-54.

Drllon, R.F., \& BitTner, L. A. 1975 Analysis of retrieval cues and release from proactive inhibition. Joumal of Verbal Learning and Verbal Behavior, 14, 616-622.

Gardiner, J. M., Craik, F.I.M., \& Birtwistle, J. 1972 Retrieval cues and release from proactive inhibition. Journal of Verbal Learning and Verbal Behavior, 11, 778-783.

Hawkins, H. L., Pardo, V.J., \& Cox, R. D. 1972 Proactive interference in short-term recognition: Trace interaction or competition. Journal of Experimenial Psychology, 92, 43-48.

Keppel, G., \& Underwood, B.J. 1962 Proac- 
tive inhibition in short-ferm retention of single irems. Journal of Verbal Learning and Verbal Behavior, 1, 153-161.

Loftus, G. R, \& PATJerson, K. K. 1975 Components of short-term proactive interference. Joumal of Verbal Learning and Verbal Behavior, 14, $105-121$.

Morı, T. 1974 A study of organizational processes in free recall. Unpublished M. A. thesis, Dept. of Psychology, Hiroshima University, Japan. (In Japanese)

Peterson, L. R., \& Peterson, M.J. 1959 Shortterm retention of individual verbal items. Journal of Experimental Psychology, 58, 193-198.

Postmay, L. 1975 Verbal learning and memory. Annual Revikw of Psychology, 56, 291-335.
Tulving, E., \& Thomson, D. M. 1973 Encoding specificity and retrieval processes in episodic memory. Psychological Review, 80, 352-373.

Turvey, M. T., Mosher, D. L., \& Katz, L. 1971 Subsequent recognition of items subjected to proactive interference in short-term memory. Psychonomic Science, 26, 365-367.

Watkins, O. G., \& Watkins, M.J. 1975 Buildup of proactive inhibition as a cue-overload effect. Journal of Experimental Psychology: Human Learning and Memory, 1, 442-452.

Wickens, D. D. 1970 Encoding categories of words: An empirical approach to meaning. Psychological Review, 77, 1-15.

(Received April 16, 1979)

Japance Psychological Research

1079, Vol 21 , No. 4, 200-206

\title{
A TEST OF THE RETENTION INTERVAL HYPOTHESIS WITH A CONSTANT ITEM PRESENTATION ORDER
}

\author{
CHIZUKO IZAWA ${ }^{1}$ \\ Tulane Universily
}

\begin{abstract}
The retention interval hypolhesis was cxamined under constant and random item presentation orders re performance differences between the study-test (reinforcement-lest, RT) and anticipation methods. The retention interval hypothesis predicts either superior or equal performances under the study-test method vis-à-vis the anticipation method under a constant presentation order, in a manner similar to that under the random one, from short-term memory processes of critical items occurring in the retention interval. Eighty university students participated in a $2 \times 2$ design experiment. Overall performance dillerences between study-test and anticipation methods were nonsignificant. The present results, together with the previous ones, are in the direction expected from the hypothesis, which gained grounds for support under a constant item presentation order in addition to a random one.
\end{abstract}

Inconsistent findings in comparisons of anticipation and study-test (rcinforcement-test,

1 Support for the present study was provided, in part, by Grant MH 12979-02 of the NIMH, U.S. Public Health Service. The author is gratefully indebted to Joseph Motto who competently assisted with data collection and partial data analyses.

Reprint requests should be addressed to Chizuko Izawa, Department of $P_{\text {sychology, Tulane Univer- }}$ sity, Ncw Orleans, Louisiana 70118 U.S.A.
RT) methods have for decades generated a mystery too puzzling to be resolved. While the study-test method frequently produced superior performances vis-à-vis the anticipation method, the two methods have also repeatedly produced about the same levels of performance. For revicws of the literature see Izawa (1972, 1974, 1979b) and Izawa, Hayden, and Isham (1980), for example.

In order to account for both of these two 